\title{
Pengaruh Gaya Kepemimpinan Terhadap Kinerja Karyawan Pada PT. Gama Panca Makmur Di Tangerang
}

\author{
Farida Agustin \\ STIE Alkhaeriyah, Cilegon, Banten, Indonesia \\ Email : agustin.farida71@gmail.com
}

(Diterima: Okt 2020; Direvisi: Nov 2020; Dipublikasikan: Jan 2021)

\begin{abstract}
ABSTRAK
Penelitian ini bertujuan untuk mengetahui pengaruh gaya kepemimpinan terhadap kinerja karyawan pada PT. Gama Panca Makmur di Tangerang. Metode yang digunakan adalah explanatory research dengan sampel sebanyak 76 responden. Teknik analisis menggunakan analisis statistik dengan pengujian regresi, korelasi, determinasi dan uji hipotesis. Hasil penelitian ini variabel gaya kepemimpinan diperoleh nilai rata-rata skor sebesar 3,511 dengan kriteria baik. Variabel kinerja karyawan diperoleh nilai rata-rata skor sebesar 3,789 dengan kriteria baik. Gaya kepemimpinan berpengaruh positif dan signifikan terhadap kinerja karyawan dengan nilai persamaan regresi $\mathrm{Y}=12,275+0,730 \mathrm{X}$, dan nilai koefisien korelasi 0,780 atau memiliki tingkat hubungan yang kuat dengan nilai determinasi $60,8 \%$. Uji hipotesis diperoleh signifikansi $0,000<0,05$.
\end{abstract}

Kata Kunci: Gaya Kepemimpinan, Kinerja Karyawan 


\section{PENDAHULUAN}

Salah satu tujuan dari pembangunan bangsa Indonesia adalah menaikkan taraf hidup dan kesejahteraan seluruh rakyat Indonesia. Dalam mewujudkan hal tersebut, upaya yang ditempuh oleh pemerintahan di antaranya adalah mendorong dan mendukung pertumbuhan berbagai industri, baik disektor pemerintahan maupun swasta. Mereka harus mampu bersaing dengan terus meningkatkan produktivitasnya, efisiensi, efektifitas dan kinerja perusahaan. Hal ini dilakukan untuk mempertahankan kelangsungan hidup perusahaannya.

Dalam setiap perusahaan peranan manusia sangatlah dominan karena melalui peranan manusia tersebut dapat saling bekerjasama atau dengan yang lainnya untuk mencapai tujuan dengan memanfaatkan segala sumber daya yang ada. Manusia yang bekerja dalam sebuah perusahaan, menyumbangkan tenaganya baik fisik maupun pikiran dan mendapatkan imbalan atau balas jasa sesuai dengan peraturan atau perjanjian disebut sebagai karyawan.

Sumber daya manusia merupakan salah satu faktor utama yang perlu dikelola dengan baik dan dilakukan secara professional agar hasil sumber daya manusia yang dihasilkan nantinya dapat meningkatkan kinerja dari individu dan perusahaan. Namun kunci dari keberhasilan dalam pengelolaan tersebut terutama bagi para karyawan salah satunya adalah bagaimana kepemimpinan yang digunakan oleh seorang pemimpin. Maka dari itu, organisasi memerlukan pemimpin yang mampu menjadi motor penggerak yang mendorong perubahan organisasi.

Peranan kepemimpinan sangat strategis dan penting dalam sebuah organisasi sebagai salah penentu keberhasilan dalam pencapaian misi, visi, dan tujuan suatu organisasi. Maka dari itu, tantangan dalam mengembangkan strategi organisasi yang jelas terutama terletak pada organisasi di satu sisi dan tergantung pada kepemimpinan. Pemimpin harus mampu memberikan wawasan, membangkitkan kebanggaan, serta menumbuhkan sikap hormat dan kepercayaan dari bawahannya. Kepemimpinan seorang pemimpin akan mampu membedakan karakteristik suatu organisasi dengan organisasi lain. Setiap individu memliki kebutuhan dan keinginan yang berbeda-beda. Setiap individu memliki tingkat keahlian yang berbeda pula.

Gaya Kepemimpinan adalah
cara seorang pemimpin
mempengaruhi prilaku bawahan, agar mau bekerja sama dan mau bekerja secara produktif untuk mencapai tujuan organisasi. Kepemimpinan yang efektif adalah pemimpin yang mengakui kekuatan-kekuatan penting yang terkandung dalam individu sedangkan kepemimpinan yang tidak efektif dan kurang memperhatikan karyawannya, biasanya menyebabkan perasaan tidak senang karyawan terhadap atasan yang diwujudkan dalam bentuk sikap bermalasmalasan dalam bekerja dan kurang bersemangat dalam menanggapi setiap tugas yang diberikan oleh pimpinan.Berdasar data prasurvey masih ada karyawan yang semangat dalam bekerjanya masih rendah. Rendahnya semangat kerja karyawan 
terjadi disinyalir karena banyak karyawan yang sering tidak masuk kantor karena sakit, ijin, alfa ataupun terlambat, ini akan menyebabkan terjadinya penurunan kinerja perusahaan.

Besarnya dampak yang ditimbulkan oleh penurunan kinerja karyawan menjadi tantangan tersendiri bagi peranan seorang manajer atau pimpinan untuk mengatasi permasalahan tersebut. Dalam kenyataannya tidak semua pimpinan berperan baik atau mampu menciptakan iklim atau suasana kerja yang kondusif dan kekeluargaan, banyak dijumpai pimpinan dalam kepemimpinannya bersikap egois, tidak mau bersikap koperatif, tidak mau berkorban dan tidak mau memberikan dorongan untuk memberi semangat kerja pada karyawan.

Pada dasarnya kinerja yang baik adalah kinerja yang mengikuti tata cara atau prosedur sesuai standar yang telh ditetapkan oleh setiap organisasi. Setiap organisasi mengharapkan agar anggotanya menunjukkan kinerja yang optimal dalam menunjang tercapainya tujuan yang telah ditetapkan sebelumnya. Oleh karena itu, maslah yang berkaitan dengan kinerja harus mendaptkan perhatian dari pihak manajemen bila hendak mencapai tujuan. Kinerja adalah suatu hasil kerja yang dicapai seseorang dalam melaksankan tugas-tugas yang dibebankan kepadanya yang didasarkan atas kecakapan, pengalaman dan kesungguhan sert waktu.

PT. Gama Panca Makmur sebagai salah satu perusahaan retail dengan banyaknya outlet di Indonesia harus bisa mempertahankan keberadaannya sebagai salah satu perusahaan penyedia baju tenun khas Sukabumi di Indonesia. Salah satu bagian perusahaan yang penting berada pada barisan paling depan yaitu pelayanan terhadap pelanggan. Perusahaan ini bergerak di bidang retail yang perkembangannya berjalan dengan kemajuan yang sangat pesat. Konsumen yang puas bukan saja akan kembali membeli dan menggunakan baju tenun tapi juga akan menyebarkan kepuasannya dan merekomendasikan baju tenun kepada orang lain. Sebaliknya, konsumen yang kecewa dan tidak puas justru akan cenderung menginformasikan sisi buruk perusahaan sehingga tidak membeli. Oleh sebab itu sangat dibutuhkan frontliner untuk menjembatani antara perusahaan dan konsumennya.

Dalam kenyataan dilapangan berdasarkan pengamatan awal, adapun permasalahan yang timbul di PT. Gama Panca Makmur yaitu pemimpin kurang memberikan kesempatan kepada bawahan untuk dapat berekspresi mengembangkan dirinya dengan mencoba menyelesaikan permasalahan lama dengan inovasi dan ide dari para karyawan, respon karyawan terhadap karyawan masih rendah, kepemimpinan perlu dioptimalkan dalam meningkatkan kinerja karyawan, peranan kepemimpinan belum efektif terhadap peningkatan kinerja karyawan.

Berdasarkan uraian di atas maka penulis tertarik untuk meneliti permasalahan mengenai "Pengaruh Gaya Kepemimpinan Terhadap Kinerja Karyawan pada PT. Gama Panca Makmur di Tangerang." 
TINJAUAN PUSTAKA

\section{Gaya Kepemimpinan}

Menurut Hasibuan (2016) yang dimaksud Gaya Kepemimpinan adalah cara seorang pemimpin mempengaruhi perilaku bawahan, agar mau bekerja sama dan mau bekerja secara produktif untuk mencapai tujuan organisasi. Sedangkan menurut Veithzal Rivai (2004) Gaya kepemimpinan adalah sekumpulan ciri yang digunakan pimpinan untuk mempengaruhi bawahan agar sasaran organisasi tercapai.

\section{Kinerja Karyawan}

Menurut Hasibuan (2016) yang dimaksud Kinerja adalah suatu hasil kerja yang dicapai seseorang dalam melaksanakan tugas-tugas yang dibebankan kepadanya yang didasarkan atas kecakapan, pengalaman dan kesungguhan serta waktu.

\section{METODE PENELITIAN}

\section{Populasi}

Populasi dalam penelitian ini berjumlah 76 responden PT. Gama Panca Makmur di Tangerang.

\section{Sampel}

Teknik pengambilan sampling dalam penelitian ini adalah sampel jenuh, dimana semua anggota populasi dijadikan sebagai sampel. Dengan demikian sampel dalam penelitian ini sampel yang digunakan berjumlah 76 responden.

\section{Jenis Penelitian}

Jenis penelitian yang dipakai adalah asosiatif, dimana tujuannya adalah untuk mengetahui atau mencari keterhubungan antara variabel independen terhadap variabel dependennya.

\section{Metode Analisis Data}

Dalam menganalisis data digunakan uji validitas, uji reliabilitas, analisis regresi linier sederhana, analisis koefisien korelasi, analisis koefisien determinasi dan pengujian hipotesis.

\section{HASIL PENELITIAN}

\section{Analisis Deskriptif}

Pada pengujian ini digunakan untuk mengetahui skor minimum dan maksimum skor tertinggi, ratting score dan standar deviasi dari masing-masing variabel. Adapun hasilnya sebagai berikut:

Tabel 1. Hasil Analisis Descriptive Statistics

Descriptive Statistics

\begin{tabular}{l|r|r|r|r|r} 
& N & Minimum & Maximum & Mean & Std. Deviation \\
\hline Gaya kepemimpinan (X) & 76 & 30 & 48 & 35.11 & 3.982 \\
\hline Kinerja Karyawan (Y) & 76 & 32 & 48 & 37.89 & 3.726 \\
\hline Valid N (listwise) & 76 & & & & \\
\hline
\end{tabular}

Gaya kepemimpinan diperoleh varians minimum sebesar 30 dan varians maximum 48 dengan ratting score sebesar 3,511 dengan standar deviasi 3,982. Skor ini termasuk pada rentang sakala 3,40 - 4,19 dengan kriteria baik atau setuju.

Kinerja karyawan diperoleh varians minimum sebesar 32 dan varians maximum 48 dengan ratting score sebesar 3,789 dengan standar deviasi 3,726. Skor ini termasuk pada rentang sakala 3,40 
- 4,19 dengan kriteria baik atau setuju

\section{Analisis Verifikatif}

Pada analisis ini dimaksudkan untuk mengetahui pengaruh variabel independen terhadap variabel dependen. Adapun hasil pengujian sebagai berikut:

Tabel 2. Hasil Pengujian Regresi Linier Sederhana.

\section{Coefficients $^{\mathrm{a}}$}

Unstandardized

Coefficients

\begin{tabular}{|c|c|c|c|c|c|}
\hline \multirow[b]{2}{*}{ Model } & \multicolumn{2}{|c|}{ Coefficients } & \multirow{2}{*}{$\begin{array}{c}\text { Coefficients } \\
\text { Beta }\end{array}$} & \multirow[b]{2}{*}{$\mathrm{t}$} & \multirow[b]{2}{*}{ Sig. } \\
\hline & B & Std. Error & & & \\
\hline 1 (Constant) & 12.275 & 2.405 & & 5.104 & .000 \\
\hline Gaya kepemimpinan $(\mathrm{X})$ & .730 & .068 & .780 & 10.720 & .000 \\
\hline
\end{tabular}

Berdasarkan hasil pengujian pada tabel di atas, diperoleh persamaan regresi $\mathrm{Y}$ $=12,275+0,730 \mathrm{X}$. Dari persamaan tersebut dijelaskan sebagai berikut:

1) Konstanta sebesar 12,275 diartikan jika gaya kepemimpinan tidak ada, maka telah terdapat nilai kinerja karyawan sebesar 12,275 point.

2) Koefisien regresi gaya kepemimpinan sebesar 0,730 , angka ini positif

\section{a. Analisis Regresi Linier Sederhana}

Uji regresi ini dimaksudkan untuk mengetahui perubahan variabel dependen jika variabel independen mengalami perubahan. Adapun hasil pengujiannya sebagai berikut:

Tabel 3. Hasil Pengujian Koefisien Korelasi Gaya kepemimpinan Terhadap Kinerja Karyawan.

\section{Correlations $^{\mathrm{b}}$}

Gaya

kepemimpinan Kinerja Karyawan

\begin{tabular}{llrrr} 
& & $(\mathrm{X} 1)$ & \multicolumn{2}{c}{$(\mathrm{Y})$} \\
\hline Gaya kepemimpinan $(\mathrm{X})$ & Pearson Correlation & 1 & $.780^{* *}$ \\
\cline { 2 - 4 } & Sig. (2-tailed) & & .000 \\
\hline Kinerja Karyawan (Y) & Pearson Correlation & $.780^{* *}$ & 1 \\
\cline { 2 - 4 } & Sig. (2-tailed) & .000 & \\
\hline
\end{tabular}

$\begin{array}{ccl}\text { Berdasarkan } & \text { hasil } & \text { hubungan yang kuat terhadap } \\ \text { pengujian diperoleh } & \text { nilai } & \text { kinerja karyawan. }\end{array}$

korelasi sebesar 0,780 artinya

gaya kepemimpinan memiliki 
c. Analisis

Determinasi

Analisis

determinasi dimaksudkan untuk mengetahui

besarnya persentase pengaruh dari variabel independen terhadap variabel dependen. Adapun hasil pengujian sebagai berikut:

Tabel 4. Hasil Pengujian Koefisien Determinasi Gaya kepemimpinan Terhadap

Kinerja Karyawan.

Model Summary

\begin{tabular}{lr|r|rr|r} 
Model & R & R Square & \multicolumn{2}{c|}{$\begin{array}{c}\text { Adjusted R } \\
\text { Square }\end{array}$} & \multicolumn{2}{c}{$\begin{array}{c}\text { Std. Error of the } \\
\text { Estimate }\end{array}$} \\
\hline 1 & $.780^{\mathrm{a}}$ & .608 & .603 & 2.348 \\
\hline
\end{tabular}

Berdasarkan hasil pengujian diperoleh nilai determinasi sebesar 0,608 artinya gaya kepemimpinan memiliki kontribusi pengaruh sebesar $60,8 \%$ terhadap kinerja karyawan, sedangkan sisanya sebesar 39,2\% dipengaruhi oleh faktor lain yang tidak dilakukan penelitian.

\section{d. Uji Hipotesis}

Pengujian

hipotesis dengan uji t digunakan untuk mengetahui hipotesis mana yang diterima.

Rumusan hipotesis: Terdapat pengaruh yang signifikan antara gaya kepemimpinan terhadap kinerja karyawan.

Tabel 5. Hasil Uji Hipotesis Gaya kepemimpinan Terhadap Kinerja

\begin{tabular}{|c|c|c|c|c|c|}
\hline \multirow[b]{2}{*}{ Model } & \multicolumn{2}{|c|}{$\begin{array}{l}\text { Karyawan } \\
\text { Coefficients }^{\mathbf{a}}\end{array}$} & $\begin{array}{c}\text { Standardized } \\
\text { Coefficients }\end{array}$ & \multirow[b]{2}{*}{$\mathrm{t}$} & \multirow[b]{2}{*}{ Sig. } \\
\hline & $\mathrm{B}$ & Std. Error & Beta & & \\
\hline 1 (Constant) & 12.275 & 2.405 & & 5.104 & .000 \\
\hline Gaya kepemimpinan (X) & .730 & .068 & .780 & 10.720 & .000 \\
\hline
\end{tabular}

Berdasarkan hasil pengujian pada tabel di atas, diperoleh nilai $\mathrm{t}$ hitung $>\mathrm{t}$ tabel atau $(10,720>1,993)$, dengan demikian hipotesis yang diajukan bahwa terdapat pengaruh yang signifikan atara gaya kepemimpinan terhadap kinerja karyawan diterima.

\section{PEMBAHASAN \\ PENELITIAN}

HASIL

\section{Kondisi Jawaban Responden} Variabel Gaya kepemimpinan

Berdasarkan jawaban responden, variabel gaya kepemimpinan diperoleh ratting score sebesar 3,511 berada di rentang skala 3,40 - 4,19 dengan kriteria baik atau setuju.

2. Kondisi Jawaban Responden Variabel Kinerja Karyawan

Berdasarkan jawaban responden, variabel kinerja karyawan diperoleh ratting score sebesar 3,789 berada di rentang skala 3,40 - 4,19 dengan kriteria baik atau setuju.

3. Pengaruh Gaya kepemimpinan Terhadap Kinerja Karyawan

Gaya kepemimpinan berpengaruh signifikan terhadap 
kinerja karyawan dengan persamaan regresi $\mathrm{Y}=12,275+$ $0,730 \mathrm{X}$, nilai korelasi sebesar 0,780 atau memiliki hubungan yang kuat dengan kontribusi pengaruh sebesar $60,8 \%$. Pengujian hipotesis diperoleh nilai $\mathrm{t}$ hitung $>\mathrm{t}$ tabel atau $(10,720>$ 1,993). Dengan demikian hipotesis yang diajukan bahwa terdapat berpengaruh signifikan antara gaya kepemimpinan terhadap kinerja karyawan diterima.

\section{KESIMPULAN DAN SARAN}

\section{A. Kesimpulan}

1. Variabel gaya kepemimpinan diperoleh ratting score sebesar 3,511 berada di rentang skala 3,40 - 4,19 dengan kriteria baik atau setuju.

2. Variabel kinerja karyawan diperoleh ratting score sebesar 3,789 berada di rentang skala 3,40 - 4,19 dengan kriteria baik atau setuju.

3. Gaya kepemimpinan berpengaruh signifikan terhadap kinerja karyawan dengan persamaan regresi $\mathrm{Y}=$ $12,275+0,730 \mathrm{X}$, nilai korelasi sebesar 0,780 atau kuat dan kontribusi pengaruh sebesar $60,8 \%$ sedangkan sisanya sebesar 39,2\% dipengaruhi faktor lain. Uji hipotesis diperoleh nilai $\mathrm{t}$ hitung $>\mathrm{t}$ tabel atau $(10,720>1,993)$.

\section{B. Saran}

Berdasarkan penelitian yang telah dilakukan, penulis mencoba memberikan beberapa saran yang diharapkan sebagai bahan masukkan untuk PT. Gama Panca Makmur sebagai bahan pertimbangan dalam memberikan kebijakan-kebijakan dimasa yang akan datang terkait dengan masalah-masalah yang ditemukan dalam penelitian ini. Adapun saran-saran yang akan penulis berikan adalah sebagai berikut:

1. Gaya kepemimpinan PT. Gama Panca Makmur sudah cukup baik, namun harus diperbaiki dan berjalan lebih optimal lagi, agar keputusan yang dibuat perusahaan dapat diterima dan dijalankan dengan baik oleh karyawan.

2. Dari sisi kinerja karyawan pada PT. Gama Panca Makmur sudah cukup baik, namun diharapkan perusahaan dan pimpinan lebih peka lagi terhadap hal-hal yang menimbulkan kepuasan dan kenyamanan kerja karyawan agar karyawan dapat bekerja lebih optimal lagi.

3. Pengaruh gaya kepemimpinan terhadap kinerja karyawan pada PT. Gama Panca Makmur sebaiknya lebih ditingkatkan lagi agar kinerja karyawan lebih tinggi sehingga akan berdampak kepada peningkatan perusahaan

\section{DAFTAR PUSTAKA}

Abdullah, M (2014) Manajemen dan Evaluasi Kinerja Karyawan, Yogyakarta: Penerbit Aswaja Pressindo.

Algifari. (2015). "Analisis Regresi untuk Bisnis dan Ekonomi". Yogyakarta: BPFE.

Arikunto, Suharsimi (2014). "Prosedur Penelitian Suatu Pendekatan Praktek". Jakarta: Rineka Cipta. 
Bangun, Wilson. 2012. "Manajemen Sumber Daya Manusia”. Jakarta: Erlangga

Bejo Siswanto (2013) Manajemen Tenaga Kerja Rancangan dalam Pendayagunaan dan Pengembangan Unsur Tenaga Kerja”, Bandung: Sinar Baru.

Edi Sutrisno (2016). Manajemen Sumber Daya Manusia. Jakarta: Prenadamedia Group.

Gerry Dessler (2016) Human Resources Management, Prenticehall, London: International Inc.

Handoko (2016) Manajemen Personalia dan Sumberdaya Manusia. Yogyakarta: BPFE.

Hasibuan, Malayu S.P. (2016). Manajemen Sumber Daya Manusia. Edisi Revisi. Jakarta: PT Bumi Aksara.

Hidayat, D., Prabowo, B., \& Anwar, S. (2020). Organizational Leadership and Conflict in Human Resource Management Review. Solid State Technology, 63(6), 1372-1381.

Imam Ghozali (2017). "Aplikasi Analisis Multivariate Dengan Program SPSS". Edisi Kelima. Semarang: Badan Penerbit Undip.

Jasmani, J., \& Paeno, P. (2019). The Effect of Leadership and Competence on Lecturer Performance and Its Implications on Student Learning Motivation at Pamulang University. International Journal of Advances in Social and Economics, 1(4).

Jasmani, J., \& Sunarsi, D. (2020). The Influence of Product Mix, Promotion Mix and Brand
Image on Consumer Purchasing Decisions of Sari Roti Products in South Tangerang. PINISI Discretion Review, 1(1), 165 174.

Luthans Fred (2014) Organizational Behavior, Ney York: McGrawHill, New York.

Mangkunegara, Prabu Anwar. (2016). Evaluasi Kinerja SDM. Cetakan ke tujuh, PT Refika Aditama: Bandung.

Robbins, P.S, \& Judge, A.T. (2003). Organizational Behavior. Jakarta: Salemba Empat.

Santoso, Singgih (2015). "Menguasai Statistik Multivariat”. Jakarta: PT Elex Media Komputindo.

Sedarmayanti (2016) Manajemen Sumber Daya Manusia, Reformasi Birokrasi dan Manajemen Karyawan Negeri Sipil, Cetakan Kelima, Bandung: PT Refika Aditama.

Sudjana (2014) "Metode Statistika", Bandung: Tarsido.

Sugiyono (2017), "Metode Penelitian Administrasi : dilengkapi dengan Metode $R \& D$ ”. Bandung: Alfabeta.

Sunarsi, D. (2014). Pengaruh Gaya Kepemimpinan, Disiplin dan Motivasi Terhadap Kinerja (Doctoral dissertation, Tesis. Fakultas Ekonomi Universitas Pamulang).

(2016). Hubungan Pengendalian Diri dengan Prestasi Belajar. Penelitian. Fakultas Ekonomi Universitas Pamulang.

(2017). Pengaruh Kepemimpinan Dan Budaya Organisasi terhadap Kinerja Karyawan Pada Cabang Pembantu Bank DKI Pondok 
Labu-Jakarta Selatan. JENIUS, 1(2), 21.

Sunarsi, D., Winata, H., Gunartin, G., \& Paeno, P. (2020). Analisis Gaya Kepemimpinan Kepala Desa Dalam Pengembangan Desa Cidokom Gunung Sindur Kabupaten Bogor. Jurnal Ekonomi Efektif, 2(3).

Suryani, N. L., Sularmi, L., Eka, P. D., Sunarsi, D., \& Maddinsyah, A. (2020). The Analysis of Career Development and Placement of Employee Performance in Pt. Global Means of Transindo in Jakarta.
Solid State Technology, 63(6), 1382-1389.

Veithzal Rivai (2015) Manajemen Sumber Daya Manusia Untuk Perusahaan, Jakarta: Raja Grafindo Persada.

Wibowo (2015) Manajemen Kinerja, Jakarta: PT. Raja Grafindo Persada.

Yuangga, K. D., Jasmani, J., \& Sunarsi, D. (2017). The Influence of Technology Determinism and Technology Literacy on Student Learning Outcomes (On MA Daarul Hikmah Pamulang). PINISI Discretion Review, 1(1), 23-30. 